\title{
Repair of defective resin composite restorations in primary teeth: current trends in Brazilian undergraduate Dental programs
}

\author{
Laura Teixeira Mendes*; Kethlen Pinzon de Oliveira**; Luciano Casagrande***; Tathiane Larissa \\ Lenzi $* * * *$
}

\author{
* PhD Candidate, Graduate Program in Clinical \\ Dentistry/Pediatric Dentistry, Dental School, Federal \\ University of Rio Grande do Sul \\ ** Undergraduate Student, Dental School, Federal University of \\ Rio Grande do Sul \\ *** Associate Professor, Graduate Program in Clinical \\ Dentistry/Pediatric Dentistry, Dental School, Federal \\ University of Rio Grande do Sul \\ **** Adjunct Professor, Graduate Program in Clinical \\ Dentistry/Pediatric Dentistry, Dental School, Federal \\ University of Rio Grande do Sul
}

Received April 1 $1^{\text {st }}, 2020$. Approved April 28 ${ }^{\text {th }}, 2020$.

\begin{abstract}
This study investigated the teaching of direct resin composite restoration repair in primary teeth in undergraduate dental programs within Brazil. A questionnaire relating to this topic was developed and e-mailed to 205 undergraduate dental schools between May and September 2019. Data obtained were analyzed descriptively. The response rate was $43.4 \%$ and out of those responding schools, $82 \%$ included this topic within their curriculum. Two of the most commonly reported reasons for teaching repair of resin composite restorations were dental structure preservation (95.9\%), and reduction in the risk of pulp complications $(71.2 \%)$. With regard to protocol for repair, few schools $(24.7 \%)$ taught mechanical roughening of the resin portion to be repaired with diamond burs. Conversely, phosphoric acid etching was recommended by $87.7 \%$ of schools and $76.7 \%$ indicated adhesive application into prepared surface. The most commonly taught material for repair was conventional resin composite. The teaching the repair of failed resin composite restorations has been established within the curriculum of undergraduate dental programs in Brazil. However, there is no consensus for the clinical protocol for repair.
\end{abstract}

Descriptors: Dental Restoration Failure. Education, Dental. Pediatric Dentistry. Students, Dental. 


\section{INTRODUCTION}

The simplistic approach of "if in doubt, take it out" for failed resin composite restorations is increasingly recognized by dentistry as having unreasonable costs associated with it due to the sacrifice of sound tooth tissue, and the reduction in the likelihood of continued pulp vitality ${ }^{1}$. In contrast, repair (i.e. removal of the defective part of the restoration, followed by restoration of the prepared defect) may increase the survival of resin composite restorations placed in both primary and permanent teeth ${ }^{2,3}$, prolonging the tooth retention time. Therefore, it has been considered preferable, whenever possible, to perform a repair as an alternative to restoration replacement ${ }^{4}$.

It has been shown that dentists who placed the original restoration are more likely to repair than replace an existing restoration, compared to a practitioner who is not the one who placed the defective restoration ${ }^{5}$. However, when restoration is associated with fracture, dentists tend to perform replacement ${ }^{5}$.

A survey conducted in Japan found that curriculum including repair of defective resin composite restorations was established within many of their Dental schools; however, there was no consensus regarding the repair protocol ${ }^{6}$. Furthermore, in Scandinavian countries, this topic has been included within their primary Dental degree program. The lack of clinical experience in performing repair has been identified as a barrier to the implementation of its teaching ${ }^{7}$. Although teaching repair of defective resin composite restorations has also been included in the curriculum of most schools in Canada and the United States, training is generally theoretical rather than clinical ${ }^{8}$.

A recent systematic review ${ }^{9}$ concluded that while most dentists state that they perform restoration repairs and that the majority of Dental schools teach these repairs, the proportion of restorations that are truly repaired is low. It is unclear if this gap between scientific evidence and clinical practice exists in countries not included in this review. Additionally, the factors beyond theoretical knowledge that determine a dentist's decision to perform a restoration repair remain unknown.

Repair of partially defective restorations is especially interesting in pediatric dentistry, because it is a more patient-friendly approach and reduces clinical time. Therefore, the aim of the present study was to investigate the teaching of direct resin composite restoration repair in pediatric dentistry among undergraduate Dental programs in Brazil.

\section{MATERIAL AND METHODS}

This study was approved by the Ethics Committee for Research, Federal University of Rio Grande do Sul, Brazil (CAAE: 96425018.0.0000.5347).

Undergraduate programs registered in the Ministry of Education and Culture (MEC) were potential participants in this study, totaling 469 institutions. The initial inclusion criterion was an appropriate institutional e-mail address for correspondence. A cover letter presenting a survey, along with a consent form and questionnaire, were sent via e-mail to a faculty member in the pediatric dentistry subject. E-mail addresses were obtained from the course coordinators by telephone or e-mail and were also collected from school websites or from scientific papers.

A questionnaire, adapted from previous studies $^{6,8}$, regarding the teaching of repair of partially defective resin composite restorations was used. The questionnaire included sixteen multiple-choice questions, two open-ended questions, and seven clinical cases (figure 1). Information sought out from the Dental school programs included: the teaching of resin 
composite repair techniques, the nature of this teaching, the reason(s) for including the topic in the curriculum, the clinical indications for repair, views on the longevity of resin composite repairs, and specifics regarding which techniques were taught for resin composite restoration repair. For each clinical case, the respondents were instructed to state a treatment plan from the following options: no intervention, polishing, repair, or replacement of the restoration.
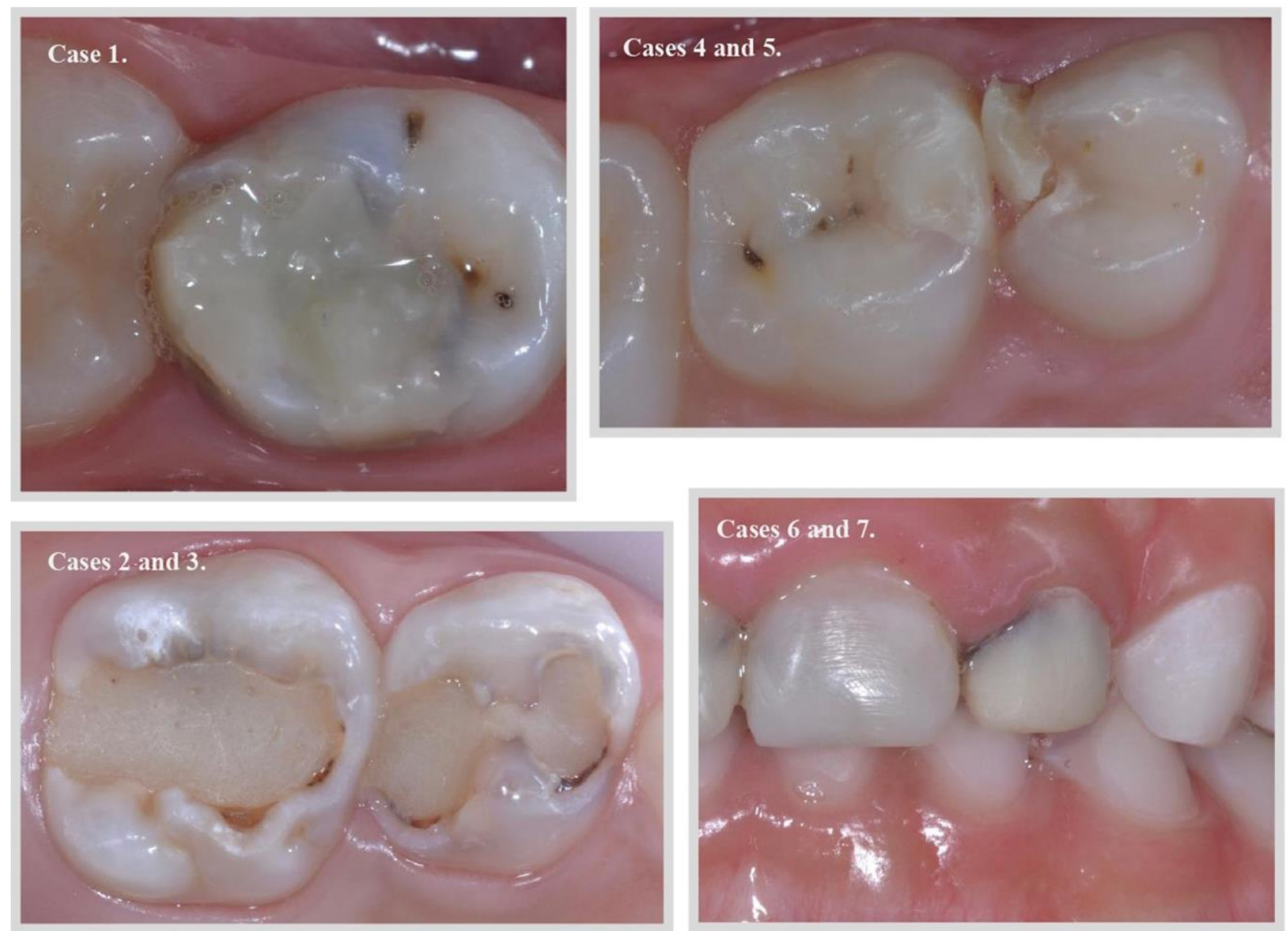

Figure 1. Pictures of the seven of partially defective resin composite restorations in primary teeth

The survey was sent out to schools via email in May 2019. Any non-responders then received the same survey e-mail 15 days later and this attempt for correspondence was repeated for a maximum of five times through September 2019. The database was periodically updated as participants' responses were received. Sampling unit was the course. When more than one questionnaire returned from the same school, the questionnaire received first was considered.
Data were summarized using descriptive statistics.

\section{RESULTS}

A flow diagram illustrates a summary of survey results from Brazilian undergraduate Dental programs (figure 2). Completed responses were received from 89 of the 205 invited schools (response rate $=43.4 \%$ ). Seventy-three schools $(82 \%)$ reported that teaching repair of defective 
resin composite restorations was included within their pediatric dentistry curriculum. Among the schools that did not teach this technique in pediatric dentistry, six reported that teaching of this topic was performed within the operative dentistry discipline; three did not include the teaching of this technique due to a time constraint within their curriculum; one school reported a lack of agreement between professors; and six schools did not indicate their reasons for not teaching this topic.

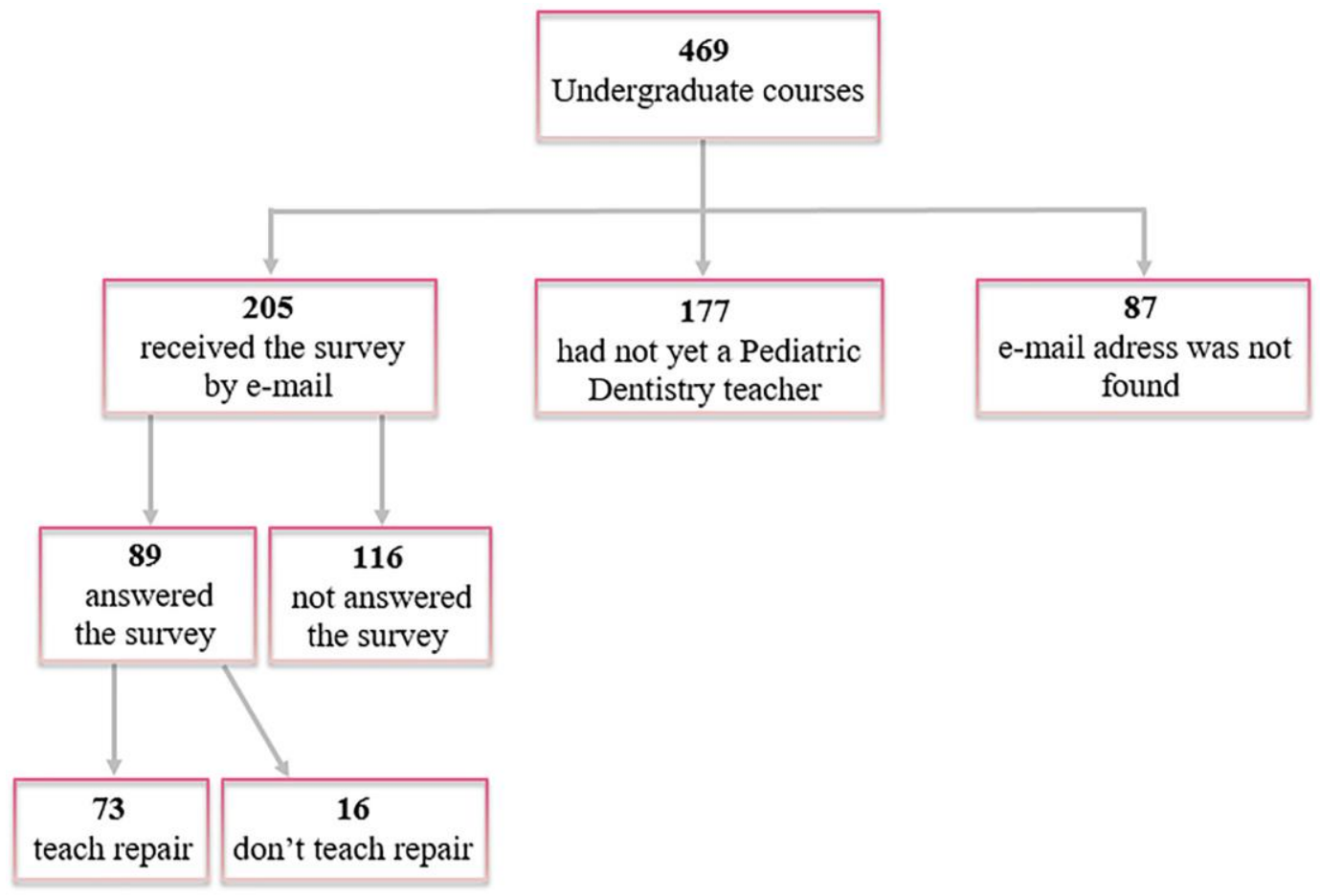

Figure 2. Flow diagram summarizing the survey results

All regions of Brazil were represented in this study (table 1). Southeastern and southern regions showed greater representation $(33.7 \%$ and $31.5 \%$, respectively), as well as, undergraduate programs from private institutions $(64 \%)$.

Table 1. Distribution by regions of the undergraduate dental courses

\begin{tabular}{lcc}
\hline Regions & Sent e-mails & Answered Questionnaires \\
& $\mathbf{N}$ & $\mathbf{N}(\mathbf{\%})$ \\
\hline North & 20 & $6(6.7)$ \\
Northeast & 45 & $18(20.2)$ \\
Central-West & 17 & $7(7.9)$ \\
Southeast & 76 & $30(33.7)$ \\
South & 47 & $28(31.5)$ \\
Total & 205 & $89(100)$ \\
\hline
\end{tabular}


Survey results are shown in table 2. Of those schools teaching the repair of resin composite restorations, their reported reasons for doing so were as follows: minimally invasive approach (90.4\%) and existing scientific evidence $(38.4 \%)$. The majority of the schools (76.7\%) said that teaching was based on theoretical and also clinical activities. The most commonly reported reasons for teaching resin composite restoration repair were: dental structure preservation $(95.9 \%)$ and reduction in the risk of pulp complications (71.2\%). The defects within restorations considered appropriate for repair rather than replacement by the largest number of schools included: marginal defects, partial loss of restoration involving up to half of the surface, and the presence of an active carious lesion involving dentin adjacent to the restoration. In addition, $86.3 \%$ of the respondents reported that they were more likely to propose repair of defective restorations in patients with difficult management and $54 \%$ of those were in primary teeth adjacent to physiological exfoliation.

With regard to surface treatment techniques used to prepare the surface of existing resin composite restorations for repair, only few schools $(24.7 \%)$ taught mechanical roughening with diamond burs, including the removal of the surface layer of material. Conversely, most schools $(87.7 \%)$ recommended phosphoric acid etching of the exposed tooth and resin composite surfaces and $76.7 \%$ of schools indicated adhesive application into the prepared surface. The material that was most commonly suggested for completing repairs was conventional resin composite. Finishing devices included finishing discs $(65.8 \%)$, abrasive polishing tips (65.8\%), and diamond finishing instruments (52.1\%). Respondents said that recall intervals based on individual caries risk were considered in the monitoring of repaired restorations through clinical exam and/or radiographic evaluation, and $54.9 \%$ of schools reported that assessment of the restoration was based on personal judgment.

For the evaluation of clinical cases, more than half of respondents opted for restorations repair for posterior teeth presenting with either an anatomic alteration or a marginal gap. However, respondents were more likely to recommend replacement in the case of a fractured restoration. Moreover, for anterior primary teeth nearest to exfoliation with subtle color and luster alteration, most respondents (69.9\%) opted for no intervention. However, $43.8 \%$ them opted for repair a restoration with marginal discoloration and color change performed in anterior primary tooth even nearest to physiological exfoliation.

Table 2. Results regarding of questions presented in the survey

\begin{tabular}{lc}
\hline Questions & $\mathbf{N}(\%)$ \\
\hline What is the definition of repair? & $11(15.1)$ \\
Sealing the margins of a defective restoration & $1(1.4)$ \\
Polishing of the restoration for improve anatomical properties and surface & $61(83.6)$ \\
Add restorative material with or unprepared in the restoration and / or dental tissues & \\
What is the reason (s) for including teaching the repair of failed resin composite restorations & \\
in the curriculum? & $26(35.6)$ \\
Clinical experience & $28(38.4)$ \\
Existing scientific evidence & $3(4.1)$ \\
Information from case reports & $66(90.4)$ \\
Minimally invasive approach & continues
\end{tabular}


How is teaching done?

continuation

Theoretical and clinical activities

$56(76.7)$

Only clinical activities

$16(21.9)$

Theoretical activities (without clinical experience)

$1(1.4)$

What criteria are used to assess the quality of restorations and the possibility of intervention?

Personal judgment (clinical and radiographic examination)

$40(54.9)$

United States Public Health Service (USPHS)

$10(13.7)$

International Dental Federation (FDI)

$21(28.8)$

Atraumatic Restorative Treatment (ART)

Type of operative field isolation your school uses for repair

Relative isolation

Absolute isolation

Isolation will depend on case

Surface treatments of existing composite restorations your school uses for repair Acid etching with phosphoric acid

Aluminum oxide abrasion

Acid etching with hydrofluoric acid

Mechanical roughening with diamond bur

No surface treatment

Materials your school uses in the repair technique

Dentine/enamel bonding agent

Flowable resin composite

Silane coupling agent

Bulk Fill resin composite

Conventional resin composite

$57(78.1)$

Glass Ionomer Cement

$26(35.6)$

Compomer

Resin sealant

Finishing techniques your school uses for repair

Diamond finishing instruments

Abrasive polishing tips

Finishing discs

Tungsten carbide finishing instruments

Polishing paste

Scalpel blade

Clinical indication(s) for repair

Tooth substance preservation

Reduced risk of pulp complications

Reduced of clinical time

$40(54.8)$

Reduced costs to the patient

$29(39.7)$

Simplification of technique

35 (47.9)

Point out the reasons for repair of resin composite restorations in primary teeth

Active caries lesion in enamel adjacent to the restoration

Active caries lesion in dentin adjacent to the restoration

Inactive caries lesion in enamel (cavitated or not) adjacent to the restoration

Inactive caries lesion in dentin adjacent to the restoration

Marginal defects

Color change in anterior teeth

Color change in posterior teeth

Marginal pigmentation in anterior teeth

Marginal pigmentation in posterior teeth 
continuation

Pigmentation of lingual/palatal surface restoration

Pigmentation of the occlusal surface restoration

Restoration pigmentation in the cervical region

Pigmentation of the restoration on proximal surface

Pigmentation involving more than one surface

Partial loss of restoration involving up to half surface

Abrasion / Attrition / Erosion

Large anterior (incisal) restoration fracture

Large anterior restoration fracture (proximal)

Large anterior restoration fracture (proximal / incisal)

Large posterior restoration fracture (occlusal)

Large posterior restoration fracture (proximal)

What is the acceptable survival of a repaired primary teeth restoration?

Up to one year

Less than three years

Three to five years

$23(31.5)$

More than five years

$10(13.7)$

Point out the factors that influence the indication of restoration repair in primary teeth

Patient age

Early childhood patients

Patients with tooth nearest to physiological exfoliation

Length of stay of deciduous tooth in the arch

Beginning of the biological cycle

End of the biological cycle

Child behavior

Patients with difficult management

Collaborating patient

Clinical situation 1. Male patient, six-year old, presenting atypical restoration in the tooth \#75

No intervention

Restoration polish

Restoration repair

Restoration replacement

Clinical situation 2. Female patient, five-year old, with restorations in the teeth \#54.

No intervention

Restoration polish

Restoration repair

Restoration replacement

No intervention

Restoration polish

Restoration replacement

Clinical situation 4. Female patient, seven-year old, presenting occluso-proximal restoration in the teeth \#54

No intervention

Restoration polish

Restoration repair

Restoration replacement 
continuation

Clinical situation 5. Female patient, seven-year old, presenting occluso-proximal restoration in the teeth \#55

No intervention

Restoration polish

Restoration repair

Restoration replacement

Clinical situation 6. Male patient, six-year old, with composite restoration in teeth \#61

No intervention

Restoration polish

Restoration repair

Restoration replacement

Clinical situation 7. Male patient, six-year old, with composite restoration in teeth \#62

No intervention

Restoration polish

Restoration repair

\section{DISCUSSION}

This is, to the best of our knowledge, the first survey to investigate if and how repair of resin composite restorations in primary teeth is taught in Brazilian undergraduate Dental programs. As with all questionnaire-based surveys, there is a risk in response reliability and a potential for nonresponse bias. This survey had a $43.4 \%$ response rate, which is similar to the response rates of other Brazilian Dental questionnaire-based surveys ${ }^{10,11}$. It is important to note that previous surveys were conducted in countries with a limited number of schools, i.e., 12 Scandinavian schools ${ }^{7}$ and 17 UK and Irish Dental schools ${ }^{12}$. In our study, 89 out of 205 schools responded to the surveys.

Our results indicate that most undergraduate Dental schools $(82.0 \%)$ teach repair of resin composite restorations performed in primary teeth. The main reasons for repair teaching were tooth substance preservation and reduced risk of harmful effects on the pulp. This is in line with surveys conducted in undergraduate Dental schools in Scandinavian countries ${ }^{7}$, the United Kingdom and Ireland $^{12}$, Japan 6 , and the United States and Canada ${ }^{8}$.
The National Curriculum Guidelines ${ }^{13}$ establish that undergraduate teaching should be based on the Pedagogical Project of each institution. This should be built collectively, centered on the student as the subject of learning for integral training and supported by the professor as mediator of the teaching-learning process. The majority of the schools reported that this training was based on theoretical and clinical activities, with previous surveys ${ }^{7,8}$ corroborating these findings. More experienced clinicians with knowledge of repair restorations repaired at a more frequent rate than clinicians with insufficient clinical training and/or theoretical knowledge. Additionally, negative experiences with repairs have been identified as a barrier to performing further repairs ${ }^{9}$. The clinical decision to perform a repair versus a replacement of defective restorations is not clear cut ${ }^{14}$. Nevertheless, the general consensus tends to favor restoration repair given its numerous advantages; including a minimally invasive approach to treatment and avoidance of unnecessary loss of tooth tissue and pulpal damage 9 . Many factors including patient's age, caries risk, frequency of dental appointments, 
affected tooth, number of restoration's surfaces, size of defect, and caries lesion depth influence dentists' decision to repair restorations ${ }^{9}$. In the current study, marginal defects, partial loss of restoration involving up to half of the surface, and presence of active carious lesion involving dentin adjacent to the restoration were the main indicators for repair. Moreover, $47.9 \%$ of respondents chose restoration repair when there were adjacent active caries lesions in enamel. The diagnosis of recurrent caries is the main reason for restoration replacement ${ }^{15}$. It has been shown that the presence of recurrent caries influences the decision to intervene, and this leads to restoration replacement in most cases ${ }^{16}$. Although recurrent caries are histologically similar to primary caries, the clinical diagnosis for evaluating the presence of caries or staining around restoration margins is a challenge for dentists and it is a subjective process. Moreover, the presence of demineralization around restoration margins by itself is not an indicator for restoration replacement ${ }^{17}$.

Most schools reported that the evaluation of the restorations is based on personal judgment, which may lead to unnecessary re-intervention. The use of standardized criteria such as United States Public Health Service (USPHS) ${ }^{18}$ and International Dental Federation (FDI) ${ }^{17}$ could be useful for assessment of restorations placed by clinicians in their own practices. Further, dental students should be trained to use these guidelines as part of a clinical evaluation to determine whether a restoration can be maintained or whether it needs repair or replacement ${ }^{17}$. According to the FDI criteria $^{17}$, restorations with cavitation and suspected undermining caries localized and accessible may be repaired while restorations with deep caries or exposed dentin, which is not accessible, must be replaced.

The majority of respondents reported that they were more likely to indicate repair of failed restorations for either primary teeth nearest to physiological exfoliation or for failed restorations in patients with difficult management. There was a consensus that the acceptable survival time for repaired restorations is less than three years. A retrospective study ${ }^{2}$ showed that the longevity of adhesive restorations placed in high caries risk children up to 36 months was $34.8 \%$. Conversely, the survival of repaired restorations at 36 months reached $43.7 \%$, providing evidence that repair increases the survival of failed restorations in primary teeth ${ }^{2}$.

Even though repair of defective restorations is particularly beneficial for children with difficult management, due to the simple and quick nature of this procedure, it can also benefit all pediatric patients with a defective restoration. In the evaluation of the clinical cases, it important to note that with the exception of fractured restorations, there was a tendency to opt for repair instead of replacement in failed restorations placed in primary molars. Additionally, $43.8 \%$ of respondents opted for restoration repair of anterior primary teeth nearest to physiological exfoliation with marginal discoloration and color change. Clinicians tend to intervene more for esthetic reasons even in situations where no intervention would be the best decision-making. Moreover, it has been well established that the treatment decision is also influenced by 'professional profile', some being more 'reactive' (do not act until the problem occurs) and others being more 'proactive' 19 .

In our study, there was no consensus regarding the clinical protocol for repair. Few schools $(24.7 \%)$ taught diamond bur mechanical roughening to the existing resin composite restoration. The goal of this physical treatment is to improve mechanical attachment between aged and new (repair) composite ${ }^{20}$. On the other hand, the majority of the schools recommended phosphoric acid etching and use of an adhesive system on exposed tooth. It has been shown that the use of 
physical and chemical surface treatments on aged dental composites is beneficial in improving the bond strength of resin composite restorations ${ }^{20}$.

The use of silane coupling agents prior to adhesive application has also been proposed as an appropriate method to use as a surface treatment in repair procedures ${ }^{21-24}$. Silanes promote the union of the inorganic phase of the substrate with the organic phase of the resin of the repair $^{25}$ and facilitate the penetration of the adhesive into surface defects due their higher surface wettability 26. However, few Brazilian schools (6.8\%) recommended the use of silane coupling agent before adhesive application. Most schools teach repair techniques involving the application of conventional or flowable resin composite. While flowable materials offer advantages, including ease of placement, they also have low filler loading ${ }^{27}$. Thus, flowable composites could be used for repairing very few defects ${ }^{4}$.

Data suggest that there is no gold standard protocol or material to treating the aged resin composite surfaces before repair. As such the repair protocol may vary widely according to clinical conditions.

In cases of repair of marginal defects and gaps with flowable resin composite, phosphoric acid etching and the use of adhesives (particularly ones containing silane) are recommended ${ }^{4}$. In cases of repair of resin composite restorations with chip defects, bulk fractures, partial loss or severe wear, it is suggested the following methods should be used: roughening of the existing composite with diamond burs, acid etching, and the application of silane and adhesive, and conventional resin composite ${ }^{4}$. When facing exposed enamel and dentin, surfaces should be smoothed followed by etching with phosphoric acid and the application of adhesive and resin composite. If no dentin and only enamel surfaces are involved, a more hydrophobic bond instead of a dentin adhesive is preferable ${ }^{4}$. It is important to highlight that there is a need for randomized controlled long-term clinical trials to be able to provide an evidence-based recommendation. Teaching restoration repair in Dental school programs is advisable, as it will promote an increase in these procedures being performed by future dentists. To enhance evidencebased management of defective restorations, a set of repair guidelines should be established.

\section{CONCLUSION}

This study has established that Brazilian undergraduate Dental programs have repair of defective resin composite restorations within their curriculums. This topic is an important part of dental training, as it best serves the interests of the pediatric patient population. Here, we propose that standardized clinical care criteria need to be established for the decision to repair verses replace composite restorations, and these criteria also need to be incorporated into dental program curriculums. To achieve the first part of this goal, further studies needed to be performed to establish the optimal techniques for repair.

\section{RESUMO}

Reparo de restaurações defeituosas de resina composta em dentes decíduos: tendência atual nos cursos de graduação em Odontologia do Brasil

Este estudo investigou o ensino do reparo de restauração direta de resina composta em dentes decíduos nos cursos de graduação em Odontologia no Brasil. Um questionário referente a este tópico foi desenvolvido e enviado por e-mail para 205 cursos de Odontologia entre maio e setembro de 2019. Os dados obtidos foram analisados descritivamente. A taxa de resposta foi de $43,4 \%$ e dos cursos respondentes, $82 \%$ incluíram esse tópico em seu currículo. As duas razões mais comumente relatadas para o ensino do reparo de restaurações de resina composta foram preservação da estrutura dentária $(95,9 \%)$ e redução do risco de complicações pulpares $(71,2 \%)$. No que diz 
respeito ao protocolo para reparo, poucos instituições $(24,7 \%)$ ensinaram o desgaste mecânico da porção da resina a ser reparada com pontas diamantadas. Por outro lado, o condicionamento com ácido fosfórico da superfície preparada foi recomendado por $87,7 \%$ das instituições e 76,7\% indicaram aplicação de adesivo na superfície preparada. $\mathrm{O}$ material mais comumente ensinado para reparo foi resina composta convencional. O ensino do reparo de restaurações de resina composta com falhas foi estabelecido dentro do currículo dos cursos de graduação em Odontologia no Brasil. No entanto, não há consenso sobre o protocolo clínico para reparo.

Descritores: Falha de Restauração Dentária. Ensino Odontológico. Odontopediatria. Estudantes de Odontologia.

\section{REFERENCES}

1. Lynch CD, Blum IR, Frazier KB, Haisch LD, Wilson NHF. Repair or replacement of defective direct resin-based composite restorations. J Am Dent Assoc. 2012;143 (2):157-63.

2. Ruiz LF, Nicoloso GF, Franzon R, Lenzi TL, de Araujo FB, Casagrande L. Repair increases the survival of failed primary teeth restorations in high-caries risk children: a university-based retrospective study. Clin Oral Investig. 2020; 24(17):71-7.

3. Casagrande L, Laske M, Bronkhorst EM, Huysmans MCDNJM, Opdam NJM. Repair may increase survival of direct posterior restorations - A practice based study. J Dent. 2017;64:30-6.

4. Hickel R, Brüshaver K, Ilie N. Repair of restorations - Criteria for decision making and clinical recommendations. Dent Mater. 2013;29(1):28-50.

5. Gordan V V, Riley J, Geraldeli S, Williams OD, Spoto JC, Gilbert GH., et al. The decision to repair or replace a defective restoration is affected by who placed the original restoration: Findings from the National Dental PBRN. J Dent. 2014;42 (12):1528-34.

6. Lynch C, Hayashi M, Seow L, Blum I, Wilson N. The Management of defective resin composite restorations: current trends in Dental school teaching in Japan. Oper Dent. 2013;38(5):497-504.

7. Blum IR, Lynch CD, Wilson NHF. Teaching of the repair of defective composite restorations in Scandinavian dental schools. J Oral Rehabil. 2012;39(3):210-6.

8. Lynch CD, Blum IR, Frazier KB, Haisch LD, Wilson NHF. Repair or replacement of defective direct resin-based composite restorations: contemporary teaching in U.S. and Canadian dental schools. J Am Dent Assoc. 2012;143(2):157-63.

9. Kanzow P, Wiegand A, Göstemeyer G, Schwendicke F. Understanding the management and teaching of dental restoration repair: Systematic review and meta-analysis of surveys. J Dent. 2018;69:1-21.

10. Paranhos MC, Pires CW, Lenzi TL, Casagrande L, Rocha RO. Graduate and undergraduate teaching of primary tooth pulpectomy: A comparison among Brazilian dental schools. Pesqui Bras Odontopediatria Clin Integr. 2019;19(1):1-10.

11. Bergoli AD, Primosch RE, de Araujo FB, Ardenghi TM, Casagrande L. Pulp therapy in primary teeth--profile of teaching in Brazilian dental schools. J Clin Pediatr Dent. 2010 Winter;35(2):191-5.

12. Blum IR, Lynch CD, Wilson NHF. Teaching of direct composite restoration repair in undergraduate dental schools in the United Kingdom and Ireland. Eur J Dent Educ. 2012;16(1):e53-8.

13. Brasil. Conselho Nacional de Educação. Câmara de Educação Superior. Resolução CNE/CES 3/2002, de 19 de fevereiro de 
2002. Institui as Diretrizes Curriculares Nacionais do Curso de Graduação em Odontologia. Seç. 1 mar 4, 2002.

14. Gordan V V, Riley JL, Rindal DB, Qvist V, Fellows JL, Dilbone DA, et al. Repair or replacement of restorations: A prospective cohort study by dentists in The National Dental Practice-Based Research Network. J Am Dent Assoc. 2015;146 (12):895-903.

15. Demarco FF, Corrêa MB, Cenci MS, Moraes RR ON. Longevity of posterior composite restorations: not only a matter of materials. Dent Mater. 2012;28(1):87-101.

16. Ávila NM, Bottezini PA, Nicoloso GF, Araujo FB, Ardenghi TM, Lenzi TL, et al. Prevalence of defective restorations and factors associated with reintervention in primary teeth: A retrospective universitybased study. Int $\mathrm{J}$ Paediatr Dent. 2019;29(5):566-72.

17. Hickel R, Peschke A, Tyas M, Mjör I, Bayne $S$, Peters $M$, et al. FDI World Dental Federation - clinical criteria for the evaluation of direct and indirect restorations. Update and clinical examples. J Adhes Dent. 2010;12(4):259-72.

18. Bayne SC, Schmalz G. Reprinting the classic article on USPHS evaluation methods for measuring the clinical research performance of restorative materials. Clin Oral Investig. 2005;9(4):209-14.

19. Mjör IA, Toffenetti F. Secondary caries: a literature review with case reports. Quintessence Int. 2000;31(3):165-79.

20. Valente LL, Sarkis-Onofre R, Gonçalves AP, Fernández E, Loomans B, Moraes RR. Repair bond strength of dental composites: systematic review and meta-analysis. Int $\mathbf{J}$ Adhes Adhes. 2016;69:15-26.

21. Fornazari I, Wille I, Meda E, Brum R, Souza E. Effect of Surface Treatment, Silane, and
Universal Adhesive on Microshear Bond Strength of Nanofilled Composite Repairs. Oper Dent. 2017;42(4):367-74.

22. Fawzy AS, El-Askary FS, Amer MA. Effect of surface treatments on the tensile bond strength of repaired water-aged anterior restorative micro-fine hybrid resin composite. J Dent. 2008;36(12):969-76.

23. Eliasson S, Tibballs J, Dahl J. Effect of Different Surface Treatments and Adhesives on Repair Bond Strength of Resin Composites After One and 12 Months of Storage Using an Improved Microtensile Test Method. Oper Dent. 2014;39(5):E20616.

24. Kashi TJ, Erfan M, Rakhshan V, Aghabaigi $\mathrm{N}$, Tabatabaei F. An In Vitro assessment of the effects of three surface treatments on repair bond strength of aged composites. Oper Dent. 2011;36(6):608-17.

25. Çakir N, Demirbuga S, Balkaya H, Karadaş M. Bonding performance of universal adhesives on composite repairs, with or without silane application. J Conserv Dent. 2018;21(3):263-8.

26. Brendeke J, Ozcan M. Effect of physicochemical aging conditions on the composite-composite repair bond strength. J Adhes Dent. 2007;9(4):399-406.

27. Baroudi K, Rodrigues JC. Flowable resin composites: A systematic review and clinical considerations. J Clin Diagnostic Res. 2015;9(6):ZE18-ZE24.

\section{Correspondence to:}

Tathiane Larissa Lenzi

e-mail: tathilenzi@hotmail.com

Faculdade de Odontologia

Programa de Pós-Graduação em Odontologia

Universidade Federal do Rio Grande do Sul

Ramiro Barcelos 2492, Santa Cecília

90035-003 Porto Alegre/RS Brazil 